\title{
Alizarine Derivatives as Corrosion Inhibitors for Aluminum in Alkaline Media. Studies on Corrosion Inhibitor for Aluminum in Alkaline Media(Part 7)*
}

\author{
Hiroko MiH A R a and Yasumasa HA Y A KA W A \\ Dept. of Chemistry, College of Science and Engineering, \\ Aoyama Gakuin University \\ 576 Megurisawa-machi, Setagaya-ku, Tokyo
}

Received July 12, 1967

\section{Introduction}

Some chelating agents inhibit the corrosion of aluminum in an alkaline solution. From experimental results, $o$-hydroxyazo derivatives $^{1)}$, 8-hydroxyquinoline derivatives $^{2}$ ) and $\beta$-diketones ${ }^{3)}$, were clarified to inhibit the corrosion only in the case of additives having structures to form insoluble chelates at a $\mathrm{pH}$ range of the chelate formations.

While, in cases of polycarbonic acids ${ }^{4}$ and of 0 -hydroxyazobenzene derivatives ${ }^{4}$ ) having sulfonate radical5), not only inhibitive effects were observed but the promotions of corrosion were seen.

In this paper, the effect of alizarine derivatives are reported on the corrosion inhibition of aluminum in alkaline media.

* The original written in Japanese can be seen in Denki-Kagaku 35, 502 (1967).

\section{Experimental}

\subsection{Specimens}

An aluminum foil of $0.3 \mathrm{~mm}$ thick, $2 \times 5 \mathrm{~cm}$ in area and $99.8 \%$ in purity was degreased with use of surface active agents at $60 \sim 80^{\circ} \mathrm{C}$ and washed by water and alcohol. After drying, both surfaces of aluminum except the area of $1 \mathrm{~cm}^{2}$ on one surface were covered by an electric insulating resin.

Alizarine derivatives used for this experiment are listed in Table 1. Anthraquinone having a structure similar to alizarine but having no radical to form a chelate with metals was used for a referrenæe.

\subsection{Alkaline Media}

$150 \mathrm{ml}$ of diluted $\mathrm{NaOH}$ solution was added with chelating agents and regulated at a certain $\mathrm{pH}$. In case of the chelating agents being insoluble in alkaline solution, a nonionic surface active agent was co- 
used. Temperature of the bath was regulated at $30^{\circ} \mathrm{C}$.

\subsection{Measurements}

The corrosion potential of aluminum was measured with a saturated calomel electrode for about 2 hrs. after an immersion of metal.

Polarization curves were obtained with use of a platinum electrode after the potential was reached the steady state value, and then Tafel points were obtained from the curves. Outline of the experimental apparatus is shown in Fig. 1.

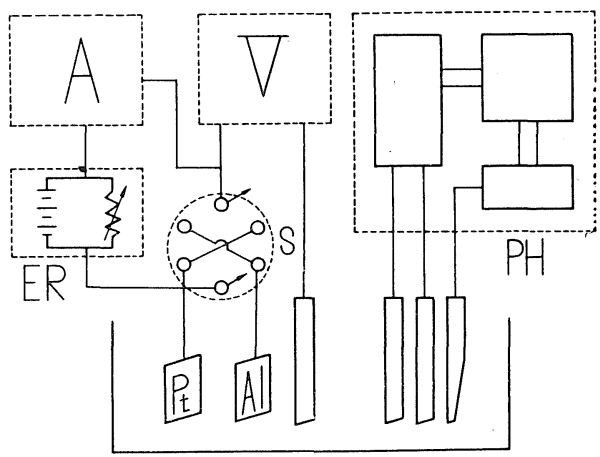

Fig. 1 Experimental apparatus

Table 2 Corrosion Potential (aft:r $2 \mathrm{hrs)}$

\begin{tabular}{c|c|c|c|c}
\hline \multirow{2}{*}{ No. of additive } & \multicolumn{4}{|c}{ Comosioñ potential (V vs, S.C.E.) } \\
\cline { 2 - 5 } & $\begin{array}{c}\text { at } \mathrm{pH} \\
12.0\end{array}$ & $\begin{array}{c}\text { at } \mathrm{pH} \\
10.3\end{array}$ & $\begin{array}{c}\text { at } \mathrm{pH} \\
9.4\end{array}$ & $\begin{array}{c}\text { at } \mathrm{pH} \\
8.2\end{array}$ \\
\hline \multirow{2}{*}{1} & -1.21 & -0.90 & -0.40 & -0.38 \\
\hline $1^{\prime}$ & -1.25 & -1.32 & -1.20 & -0.80 \\
\hline 2 & -1.30 & -1.20 & -0.90 & -0.30 \\
\hline 2 & -1.30 & -1.30 & -1.12 & -0.64 \\
\hline 3 & -1.32 & -1.24 & -0.30 & -0.30 \\
\hline 4 & -1.28 & -1.00 & -0.20 & -0.33 \\
\hline 5 & -1.28 & -1.30 & -1.00 & -0.36 \\
\hline 6 & -1.30 & -1.24 & -1.24 & -0.88 \\
\hline 7 & -1.28 & -1.32 & -1.10 & -0.68 \\
\hline no additive & -1.30 & -1.30 & -1.13 & -0.65 \\
\hline surface \\
active agent & - & - & -1.12 & -0.60 \\
\hline
\end{tabular}

Table 1 Additives Used

\begin{tabular}{l|l|l|l|}
\hline No. & Chelating agents & Alizarine \\
\hline 1 & $\begin{array}{l}\text { Sodium aliza- } \\
\text { rine sulfonate }\end{array}$ & 290 \\
\hline
\end{tabular}

\section{Results and Discussion}

\subsection{Corrosion Potential}

The values of potentials after $2 \mathrm{hrs}$. immersion are listed in Table 2.

At $\mathrm{pH} 12.0$ : All of the potentials after 2 hrs. immersion showed similar values. No shifts of potentials toward more noble side in the presence of additives were observed, therefore, inhibitive effects of additives were not found. The additives having a sulfonate radical show- 
ed similar phenomena, At this $\mathrm{pH}$, aluminum were corroded violently and the dissolved $\mathrm{Al}^{3+}$ ion formed chelate compounds with chelating agents in the solution and any chelate formations could not find on the surface of aluminum.

At $\mathrm{pH} 10.3$ : The order of potentials after 2 hrs. immersion was as follows, No. $1>$ No. $4>$ No. $2>$ No. 3 , No. $6>$ no additive, No. 2', No. 5>No. 7; No. 1'>No. 5. At this $\mathrm{pH}$, chelating agents added almost showed inhibitive effects on aluminum. Especially, the potential of aluminum in presence of No. 1 shifted remarkably toward more noble potential side, and the surface of the metal kept metallic lustre and inhibitive effects were shown. In case of No. 1' having sulfonate radical showed small effect to corrosion and the potential shifted toward less noble potential side. In this $\mathrm{pH}$ range the corrosion of aluminum were not violent and the formation velocity of $\mathrm{Al}^{3+}$ ions into solution were slow. The inhibition of corrosion was considered to play a roll of the additives to form chelates on the surface of metal in a great extent.

At $\mathrm{pH} 9.4$ : The order of potentials after 2 hrs. was as follows, No.4>No.3> No. $1>$ No. $2>$ No. $>>$ No. $7>$ no additive, No. $2^{\prime}>$ No. $1^{\prime}>$ No. 6 additives showed inhibitive effects but in cases of Nos. 6 and 1 ' the corrosion were promoted. At this $\mathrm{pH}$ the inclinations of corrosion inhibition were similar to those at $\mathrm{pH} 10.3$.

At $\mathrm{pH} 8.2$ : The order of potentials after 2 hrs. was as follows, No.2, No.3> No.4>No.5>No.1 $>$ no additive, No. 2' $>$ No. $7>$ No. $1^{\prime}>$ No.6. Small effects were shown at this region. But any remarkable changes were not seen on the surface of metal.

At $\mathrm{pH} 2.7$ : The corrosion potentials after 2 hrs. showed no inhibitive effect of additives for aluminum.
Table 3 Corrosion current density

\begin{tabular}{c|c|c|c}
\hline \hline \multirow{2}{*}{ No. of additive } & \multicolumn{3}{|c}{ Corrosion current density $\left(\mu \mathrm{A} / \mathrm{cm}^{2}\right)$} \\
\cline { 2 - 4 } & at $\mathrm{pH} \mathrm{12.0}$ & at $\mathrm{pH} 10.3$ & at $\mathrm{pH} \mathrm{9.4}$ \\
\hline 1 & 250 & 7.1 & 0.25 \\
\hline $1^{\prime}$ & 400 & 115 & 76 \\
\hline 2 & 230 & 32 & 8.5 \\
\hline 2 & 1200 & 140 & 31 \\
\hline 3 & 980 & 40 & 6.4 \\
\hline 4 & 1080 & 20 & 1.5 \\
\hline 5 & 1450 & 290 & 21 \\
\hline 6 & 880 & 265 & 110 \\
\hline 7 & 400 & 80 & 8.2 \\
\hline $\begin{array}{c}\text { no addtive } \\
\text { surface } \\
\text { active agent }\end{array}$ & 190 & 52 & 11 \\
\hline & - & - & 11 \\
\hline
\end{tabular}

\subsection{Polarization Characteristics}

The values of corrosion current densities obtained from polarization curves are listed in Table 3.

At $\mathrm{pH} 12.0$ : The corrosion current densities of inhibited aluminum were larger than that of uninhibited aluminum.

By the addition of additives having a sulfonate radical no effects on the polarization behavior of aluminum were observed.

At $\mathrm{pH} 10.3$ : The order of corrosion current densities was as follows, $<$ No.1 $<$ No. $4<$ No. $2<$ No. $3<$ no additive $<$ No. 7 $<$ No.5, No.6,

where the corrosion current density of No. 1 was very small and the inhibitive effect was shown. While, in the case of No. 1' the corrosion current density showed large value and the inclination of corrosion was shown. In the cases of Nos. 5 and 6, no effects were shown.

At $\mathrm{pH} 9.4$ : The order of corrosion current densities was as follows,

No. $1<$ No. $4<$ No. $3<$ No. $7<$ No. $2<$ no additive, where especially in cases of Nos. 1 and 4 corrosion current densities decreased remarkably and the effects of corrosion inhibition were considerably observed. 
While, in the case of No.1' having a sulfonate radical the corrosion current density increased and the promotion of corrosion was seen. In cases of Nos. 5 and 6 no effects were shown.

\subsection{Observation of Surface}

In case of No. 1 the surface of aluminum still kept lustrous, and in No. 4 the surface was attached with pink dye and in both cases the film formation were observed on the surface of metal specimens.

Aluminum corroded slightly in presence of Nos. 2 and 3 before the adsorption of dyes and the potential shifts toward noble side were generally small compared with those of Nos. 1 and 4. In cases of Nos. 5 and 6 the corrosion was increased compared with the case of no additive. In case of No. 1' having sulfonate radical the corrosion was violently promoted.

In strong alkaline region, surfaces of metal were violently corroded in both cases having additive and no additive, while in neutral and acidic regions the change of surface was not shown.

\section{Conclusion}

The following conclusions were dexived from experimental results and discussion mentioned above.

1) Alizarine derivatives not having sulfonate radical act as inhibitor for aluminum corrosion in a weak alkaline region.

2) The corrosion inhibition was caused by the formation of an insoluble chelate film on the surface of aluminum.

3) Alizarine derivatives having sulfonate radical, which enable them to form soluble chelates, showed no inhibitive effect for aluminum but promoted corrosion.

\section{Literatures:}

1) Y. Hayakawa, I. Ida, This Journal 26, E 197 (1958).

2) Y. Hayakawa, T. Mitamura, S. Kaneko, ibid. 29, E 41 (1961).

3) K. Horiguchi, K. Sawamura, I. Saito, Y. Hayakawa, ibid. 34, 162 (1966).

4) K. Horiguchi, K. Tamura, Y. Hayakawa, Denki-Kagaku 34, 911 (1966).

5) I. Saito, Y. Hayakawa, ibid.35, 199 (1967). 